\title{
Biliary expression of heat shock protein: a non-specific feature of chronic cholestatic liver diseases
}

\author{
E B G Martins, R W Chapman, K Marron, K A Fleming
}

\begin{abstract}
Aim-To analyse the expression of heat shock protein (HSP) 60 in biliary epithelium in auto-immune liver conditions and also in chronic cholestatic and other liver diseases.

Methods-Hepatic expression of HSP-60 in frozen liver biopsy specimens from patients with primary sclerosing cholangitis (PSC), primary biliary cirrhosis (PBC), auto-immune hepatitis (AIH), obstructive jaundice (LDO), alcoholic liver disease (ALD), and from normal controls was studied by immunohistochemistry using the APAAP technique and confocal laser scanning microscopy.

Results-Increased expression of HSP-60 was demonstrated in the biliary epithelium of patients with PBC, LDO and, to a lesser extent, with PSC. Focal, weaker, biliary epithelial expression of HSP-60 was observed in AIH, ALD and normal liver tissue. Increased expression was also seen on Kupffer cells in LDO and in hepatocytes in areas of piecemeal necrosis in AIH.

Conclusion-Enhanced biliary expression of HSP-60 is a common feature of chronic biliary disease irrespective of aetiology and is not specific to auto-immune diseases.

(f Clin Pathol 1996;49:53-56)
\end{abstract}

Keywords: stress proteins, primary sclerosing cholangitis, primary biliary cirrhosis, chronic cholestasis.

Heat shock proteins (HSPs) are a highly conserved group of proteins present in all prokaryotic and eukaryotic cells. Their name derives from original experiments in which these proteins were induced in cells exposed to extreme heat. ${ }^{1-5}$ It is now known that they respond to many environmental stresses such as temperature changes, fever, inflammation, irradiation, viral infection, malignant transformation, exposure to heavy metal ions, ethanol, and anoxia. ${ }^{3}$ It has been suggested, therefore, that they should be called stress related proteins. Their functions are related to protection of cells against the potential damage caused by noxious stimuli. They also have important functions in folding, assembly and oligomerisation of polypeptides, and are therefore essential for cell viability. ${ }^{5}$ The HSPs are classified into families according to their size, antigen cross reactivities and sequence homologies. Among the various families is the HSP-
60 family, which includes the mycobacterial 65 kilodalton HSP. ${ }^{46}$ This HSP shares homology with a human mitochondrial protein, and the GroEL protein of Escherichia coli, ${ }^{7}$ which corresponds to what was previously described as the bacterial "common antigen" ${ }^{8}$ HSP-60 has been associated with auto-immune diseases such as rheumatoid arthritis, ${ }^{39-11}$ primary biliary cirrhosis (PBC), primary sclerosing cholangitis (PSC) ${ }^{12}$ and conditions such as alcoholic liver disease (ALD). ${ }^{1314}$ It has recently been suggested that induced biliary expression of HSP-60 in PSC and PBC may be specifically involved in the auto-immune genesis of these conditions. ${ }^{12}$ However, these studies did not exclude the possibility that this biliary expression of HSP-60 may represent a non-specific response to a variety of stresses. We therefore analysed the expression of HSP-60 in liver tissue from patients with PSC and PBC, ALD, auto-immune hepatitis (AIH), chronic extra hepatic bile duct obstruction (LDO), and from normal controls.

\section{Methods}

Liver biopsy specimens were obtained from seven cases of PBC (six with stage I-II disease), 13 of PSC (eight with stage I-II disease), seven of untreated AIH, six of LDO, and six of ALD. Six normal biopsy specimens served as controls. The biopsy specimen cores were embedded in OCT (BDH Ltd, Poole, Dorset, UK) and snap frozen in liquid nitrogen. Thin $(5 \mu \mathrm{m})$ cryostat sections were fixed with acetone at $4^{\circ} \mathrm{C}$ for 10 minutes.

\section{IMMUNOHISTOCHEMISTRY}

HSP-60 was detected using ML30, an IgG1 monoclonal antibody, diluted 1 in 1000 (a gift from Professor J Ivanyi, Tuberculosis and Related Infections Unit, Hammersmith Hospital, London). This antibody reacts with the mycobacterial $65 \mathrm{kDa} \mathrm{HSP}$ and cross reacts with a human mitochondrial $60 \mathrm{kDa}$ HSP, facilitating the study of HSP-60 expression in human tissue. ${ }^{15}$ An irrelevant antibody (mouse IgG1, Dako, High Wycombe, UK) was used as negative control. Immunohistochemistry was carried out using the APAAP technique, as described previously. ${ }^{16}$

\section{ANALYSIS}

The intensity of staining was assessed in septal, inter-lobular and proliferating bile ducts in the 
Summary of bile duct expression of HSP-60

\begin{tabular}{llll}
\hline Disease & Septal ducts & Interlobular ducts & Proliferating ducts \\
\hline PBC & $+++(100 \%)$ & $+++(100 \%)$ & $+++(100 \%)$ \\
LDO & $+++(100 \%)$ & $+++(100 \%)$ & $+++(100 \%)$ \\
PSC & $+++(100 \%)$ & $+/++(70 \%)$ & $+/++(80 \%)$ \\
AIH & $++(100 \%)$ & $+/+(60 \%)$ & $-/++(80 \%)$ \\
ALD & $+/++(100 \%)$ & $-/++(50 \%)$ & - \\
Normal liver tissue & $+/++(100 \%)$ & $-/++(50 \%)$ & -
\end{tabular}

The results are expressed as (\%) positive ducts in each group. The semiquantitative score for intensity of staining is as follows: - , negative staining; + , weak staining; ++ , moderate staining; +++ , strong staining.

different diseases. A semiquantitative scoring system for the staining intensity was used: no staining, - ; weak staining, + ; moderate staining, ++ ; and strong staining, +++ . The percentage of positive bile ducts was also assessed.

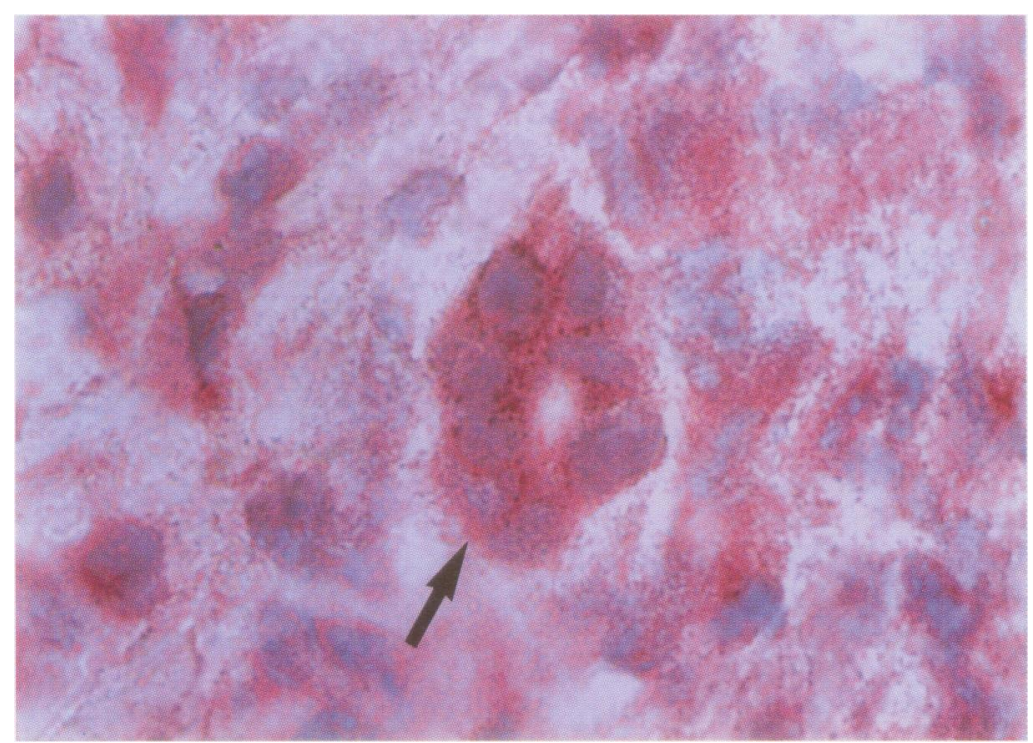

Figure 1 A bile duct (arrow) in a biopsy specimen from a patient with LDO, in which all of the bile duct epithelial cells were strongly positive for HSP-60. (Original magnification, $\times$ 100.)

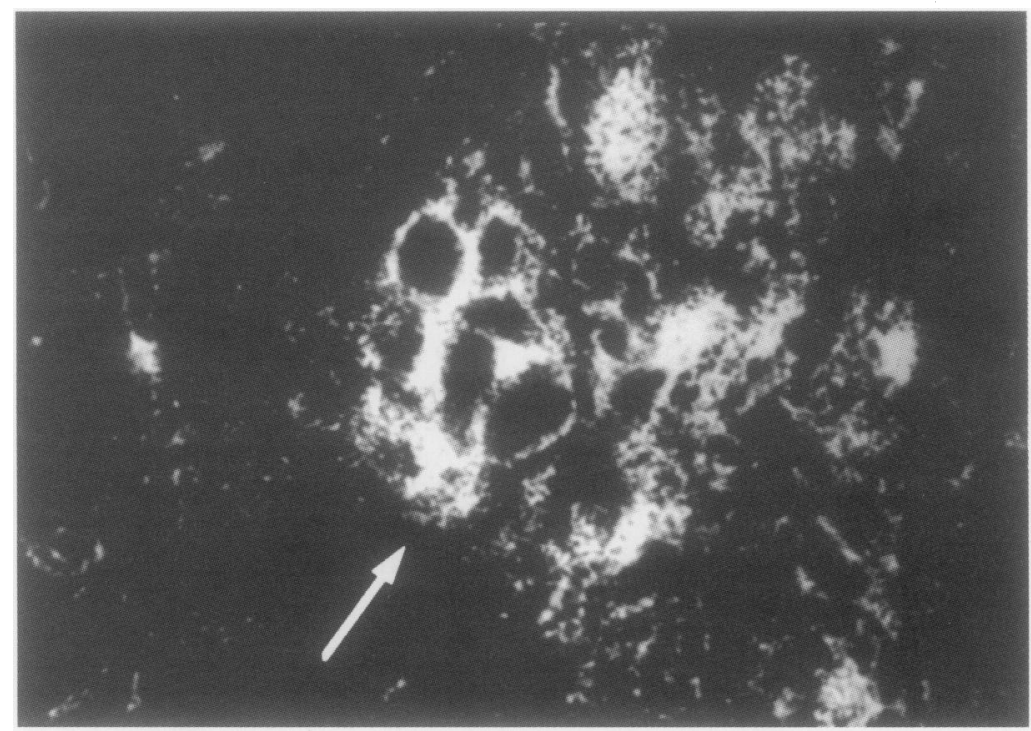

Figure 2 The same bile duct (arrow) as in fig 1, studied using CLSM. Note the granular perinuclear staining pattern. (Original magnification, $\times 120$.)

\section{CONFOCAL LASER SCANNING MICROSCOPY}

Bile ducts strongly positive for HSP-60 were analysed further using confocal laser scanning microscopy (CLSM). The light microscopy sections were used as alkaline phosphatase-fast red is a good fluorescent label for CLSM. ${ }^{17}$ This technique permits the study of epitope distribution by focusing on a single plane within the tissue section with enhanced contrast and resolution, compared with light microscopy. Individual planes may then be reconstructed to give an impression of the entire cellular distribution of HSP-60 immunoreactivity.

This study conformed to the guidelines of the Central Oxfordshire Health Authority Research Ethics Committee (COREC). Informed consent for liver biopsy was obtained from each patient.

\section{Results}

EXPRESSION OF HSP-60 IN BILE DUCTS

Epithelial cytoplasmic expression of HSP-60 was present in the septal bile ducts in all biopsy specimens, including normal liver; in normal liver, however, the staining intensity was much weaker than that observed in the diseased tissue (table). HSP-60 was expressed strongly in liver tissue from patients with PBC, LDO and PSC. Increased expression of HSP-60 was observed in all interlobular bile ducts in PBC and LDO samples (fig 1). In PSC samples there was increased expression of HSP-60 in $70 \%$ of interlobular ducts, with weak or no staining in others. These findings did not correlate with histological stage. Focal staining for HSP-60 was noted in some interlobular bile ducts in AIH, ALD and normal liver tissue samples, but the intensity of staining was weak, particularly in the normal samples. In PBC and LDO samples all proliferating bile ducts exhibited increased expression of HSP-60, and again enhanced expression was seen focally in PSC. Focal positive staining was also observed in proliferating ductules in AIH samples.

On light microscopy, epithelial staining of the bile ducts was cytoplasmic and granular, and all cells were diffusely positive. Nuclear staining was not detected. On CLSM, the pattern of staining was confirmed to be granular and cytoplasmic. The nuclei did not stain (fig 2). The HSP-60 staining pattern was similar in all of the diseased tissue studied.

\section{HEPATOCYTE STAINING}

Cytoplasmic expression of HSP-60 was observed in hepatocytes in all of the patient groups studied. Expression was focal and without any specific pattern of distribution, except for AIH where there was noticeably strong expression of HSP-60 in hepatocytes in the areas of piecemeal necrosis and adjacent to inflammatory infiltrate. These hepatocytes seemed to be undergoing degeneration or biliary transformation. The overall pattern of hepatocyte staining was slightly less granular than in the bile ducts. This was confirmed by CLSM, which demonstrated a more homogeneous cytoplasmic distribution of HSP-60. As in bile 
ducts, nuclear staining was not observed. Staining intensity was stronger in patients with liver disease than in normal controls, where negative hepatocytes were often present.

\section{KUPFFER CELLS}

HSP-60 was strongly expressed in Kupffer cells in LDO tissue samples. This staining pattern was not observed in the other liver diseases studied nor in the normal controls.

\section{INFLAMMATORY INFILTRATE}

Infiltrating portal and lobular cells were strongly positive for HSP-60, as were mononuclear cells and granulocytes. Again, the staining pattern was cytoplasmic and intensely granular. This was confirmed on CLSM. In some areas the staining intensity of the inflammatory infiltrate was stronger than that of the bile ducts and hepatocytes.

\section{Discussion}

HSPs are among the most conserved proteins in nature. They are found in all eukaryotic and prokaryotic cells. Their functions vary among different families, with HSP-60 being responsible for protein folding and oligomerisation. HSPs are also involved in removing damaged proteins from cells and in mediating receptor activation, as in the case of HSP-90 and the steroid receptor. In all cells they are essential for maintaining viability under unfavourable circumstances. Most HSPs exist in small quantities in each cell, but they can be induced by various forms of stress, when their intracellular content is greatly increased. In these instances they can be detected using immunohistochemical methods. Most antibacterial defences include reactions directed against HSPs. Accordingly, because of their shared homology with bacterial proteinsHSP- 60 shares more than $50 \%$ sequence homology with the GroEL protein of $E$ coli-it has been hypothesised that this may result in autoimmune reactions due to molecular mimicry. ${ }^{18}$ This hypothesis is supported mainly by data from studies on rheumatoid and reactive arthritis. ${ }^{91019}$ This evidence, however, is still inconclusive. ${ }^{20}$

In the present study increased expression of HSP-60 was detected in the biliary epithelium of patients with PSC, PBC and LDO. The human homologue of mycobacterial HSP-60 is a mitochondrial protein, ${ }^{7}$ and the pattern of staining we detected in biliary epithelium was granular and cytoplasmic. Nuclear staining was not observed. This distribution is consistent with the previously described mitochondrial location of HSP-60. A similar pattern of staining has been reported in other studies using the ML30 antibody. ${ }^{15}$

Recently, Broomé et $a l^{12}$ reported induced expression of HSP-60 in biliary epithelium in patients with PSC and PBC. In their study there was also some degree of biliary expression of HSP-60 in ALD and chronic hepatitis C, but to a much lesser extent than in PSC and
PBC. The same group reported the absence of biliary expression of HSP-60 in normal liver tissue. In view of these results it was suggested that this phenomenon could be directly involved in the auto-immune genesis of PSC and PBC. As bile ducts in PSC and PBC also aberrantly express HLA-DR, ${ }^{2122}$ it is possible that these cells act as antigen presenting cells and HSP- 60 could be the putative auto-antigen. In the present study, however, enhanced expression of HSP-60 was detected in the bile ducts of patients with LDO as well in those with PSC and PBC. These findings suggest that enhanced expression of HSP-60 in bile ducts may not have a primary role in biliary auto-immunity. In the patients with LDO presented herein, extra hepatic duct obstruction was caused by a variety of conditions, none of which were immune mediated. Moreover, nonspecific aberrant expression of HLA-DR has also been demonstrated in LDO. ${ }^{2122}$ If HLADR positive bile ducts present HSP-60 as an auto-antigen, one would expect manifestations of auto-immunity to occur in LDO as well as in PBC and PSC. As yet, there is no evidence to suggest that auto-immune bile duct damage occurs in LDO. Therefore, as HSPs are known to respond to a variety of stresses, it is likely that HSP-60 expression is induced non-specifically in bile ducts exposed to a variety of chronic noxious stimuli, such as chronic cholestasis, and that this is a secondary phenomenon, rather than a primary event. The intensity of the staining of the inflammatory infiltrate and Kupffer cells in LDO also suggests that the HSP-60 response is non-specific. If HSP-60 is an auto-antigen, one would expect that these cells, in view of their high HSP content, would become targets of an autoimmune reaction. At present, this does not appear to be the case. Another possibility is cross-reaction between the ML30 antibody and bacterial HSP, as these patients are more prone to biliary colonisation. This is unlikely, however, as although the ML30 epitope in mycobacteria and humans is homologous, it is not widely shared among bacteria. ${ }^{23}$

Expression of HSP-60 may be involved in the pathogenesis of PSC via an alternative mechanism. Anderson et $^{24}{ }^{24}$ demonstrated that cross-reactivity in the immune response to the mycobacterial HSP-60 can be directed against self proteins, such as HLA-DR2. Also, human $\mathrm{CD} 8+\mathrm{T}$ cells have been shown to recognise mycobacterial antigens in a HLA-B8 restricted presentation. ${ }^{25}$ Interestingly, both HLA-B8 and DR2 are strongly associated with PSC. Therefore, although HSP-60 expression was not unique to PSC, this HSP may induced autoimmune liver damage in genetically susceptible individuals. If this was the case, the auto-immune response would therefore be constrained by the expression of HLA antigens. This may also be the case for PBC but, as yet, this condition has not been closely associated with expression of a particular HLA antigen.

HSP-60 was highly expressed by hepatocytes in tissue samples from patients with $\mathrm{LDO}$, PBC, PSC, AIH, and ALD. This expression is also presumably non-specific, a supposition 
supported by the non-specific increase in circulating antibodies directed against HSP-60 in ALD, PBC and PSC. ${ }^{14}$ Similar data has been reported by Lohse et $a l,{ }^{26}$ who found increased hepatocytic expression of HSP-60 in fatty livers, and viral and auto-immune hepatitis, diseases with a very different aetiopathogenesis.

In conclusion, the results reported here suggest that the enhanced biliary expression of HSP-60 is a non-specific phenomenon, characteristic of a variety of cholestatic liver diseases, and is not a primary event solely associated with auto-immune liver diseases. The role of HSP-60 in biliary auto-immunity has yet to be determined.

E B G Martins is funded by a scholarship from CAPES, Brazilian Ministry of Education.

1 Lindquist S. The heat-shock response. Annu Rev Biochem 1986;55:1151-91.

2 Lindquist S, Craig EA. The heat-shock proteins. Annu Rev Genet 1988;22:631-77.

3 Kaufmann SHE. Heat shock proteins and the immune response. Immunol Today 1990;11:129-36.

4 Born W, Happ M, Dallas A, Reardon C, Kubo R, Shinnick $\mathrm{T}$, et al. Recognition of heat shock proteins and $\mathrm{g} / \mathrm{d}$ cell function. Immunol Today 1990;11:40-3.

5 Benjamin IJ. Stress proteins: is their application in clinical medicine on the horizon? Hepatology 1993;18:1532-4

6 Kaufmann SHE, Vath U, Thole JER, Van Embden JDA, Emmrich F. Enumeration of T cells reactive with Mycobacterium tuberculosis organisms and specific for the recombinant mycobacterial 64-kDa protein. Eur 7 Immunol 1987;17:351-7.

7 Jindal S, Dudani AK, Singh B, Harley CB, Gupta RS. Primary structure of a human mitochondrial protein homologous to the bacterial and plant chaperonins and to the 65-kilodalton mycobacterial antigen. Mol Cell Biol 1989;9:2279-83.

8 Lamb JR, Young DB. T cell recognition of stress proteins. A link between infectious and autoimmune disease. Mol Biol Med 1990;7:311-21.

9 Karlsson-Parra A, Soderstrom K, Ferm M, Ivanyi J, Kiessling R, Klareskog L. Presence of human $65 \mathrm{kD}$ heat shock protein (hsp) in inflamed joints and subcutaneous nodules of RA patients. Scand $\mathcal{f}$ Immunol 1990;31:283-8.

10 Quayle AJ, Wilson KB, Li SG, Kjeldsen-Kragh J, Oftung $\mathrm{F}$, Shinnick T, et al. Peptide recognition, $\mathrm{T}$ cell receptor usage and HLA restriction elements of human heat-shock protein (hsp) 60 and mycobacterial $65-\mathrm{kDa}$ hsp-reactive T cell clones from rheumatoid synovial fluid. Eur f Immunol 1992;22:1315-22.

11 Young RA, Elliot TJ. Stress proteins, infection, and immune surveillance. Cell 1989;59:5-8.

12 Broomé U, Scheynius A, Hultcrantz R. Induced expression of heat-shock protein on biliary epithelium in patients with primary sclerosing cholangitis and primary biliary with primary sclerosing cholangitis and
cirrhosis. Hepatology 1993;18:298-303.

13 Koskinas J, Winrow VR, Bird GL, Lau JY, Portmann BC, Blake DR, et al. Hepatic $60-\mathrm{kD}$ heat-shock protein reBlake DR, et al. Hepatic 60-kD heat-shock protein re51 .

14 Winrow VR, Bird GL, Koskinas J, Blake DR, Williams R, Alexander GJ. Circulating IgA antibody against a $65 \mathrm{kD}$ heat shock protein in acute alcoholic hepatitis. $\mathcal{F}$ Hepato 1994;20:359-63.

15 Evans DJ, Norton P, Ivanyi J. Distribution in tissue sections of the human groEL stress-protein homologue. APMIS 1990;98:437-41.

16 Cordell JL, Falini B, Erber WN, Ghosh AK, Abdulaziz $\mathrm{Z}$, MacDonald S, et al. Immunoenzymatic labelling of monoclonal antibodies using immune complexes of alkaline phosphatase and monoclonal anti-alkaline phoskaline phosphatase and monoclonal anti-alkaline phos-
phatase (APAAP complexes). F Histochem Cytochem 1984; phatase (APA

17 Murdoch A, Jenkinson EJ, Johnson GD, Owen JJT. Alkaline phosphatase-fast red, a new fluorescent label. Application in double labelling for cell surface antigen and cell cycle analysis. F Immunol Methods 1990;132:45-9.

18 Oldstone MB. Molecular mimicry and autoimmune disease. Cell 1987;50:819-20.

19 Cohen IR. Autoimmunity to chaperonins in the pathogenesis of arthritis and diabetes. Annu Rev Immunol 1991:9:56789.

20 Elson CJ, Thompson SJ. Immunity, autoimmunity and immunotherapy: new frontiers in heat shock protein research. Clin Exp Immunol 1994;98:175-7.

21 Chapman RW, Kelly PM, Heryet A, Jewell DP, Fleming KA Expression of HLA-DR antigens on bile duct epithelium in primary sclerosing cholangitis. Gut 1988;29:422-7.

22 Barbatis C, Kelly P, Greveson J, Heryet A, McGee JO. Immunocytochemical analysis of HLA class II (DR) antigens in liver disease in man. $f$ Clin Pathol 1987;40. 879-84.

23 Thole JE, Hindersson P, de-Bruyn J, Cremers F, van-derZee J, de-Cock H, et al. Antigenic relatedness of a strongly immunogenic $65 \mathrm{kDa}$ mycobacterial protein antigen with a similarly sized ubiquitous bacterial common antigen. Microb Pathog 1988;4:71-83.

24 Anderson DC, van-Schooten WC, Barry ME, Janson AA, Buchanan TM, de-Vries RR. A Mycobacterium lepraeBuchanan TM, de-Vries RR. A Mycobacterium lepraespecific human T cell epitope cross-reactive

25 Rees A, Scoging A, Mehlert A, Young DB, Ivanyi J. Specificity of proliferative response of human CD8 clones to mycobacterial antigens. Eur f Immunol 1988;18:1881-7.

26 Lohse AW, Dienes HP, Herkel J, Hermann E, van-Eden W, Meyer-zum-Buschenfelde KH. Expression of the $60 \mathrm{kDa}$ heat shock protein in normal and inflamed liver. 7 Hepatol 1993;19:159-66. 